\title{
SYNTHESIS AND CHARACTERIZATION OF POLYPROPYLENE-SILICA, ALUMINA AND TITANIA NANOPARTICLES, PREPARED BY MELTING
}

\author{
F. ORELLANA ${ }^{1 *}$, J. LISPERGUER ${ }^{1,2}$ AND C. NUNEEZ ${ }^{1}$ \\ ${ }^{\prime}$ Departamento de Química, Facultad de Ciencias, Universidad del Bio-Bio, Av. Collao 1202-Concepción-CHILE \\ ${ }^{2}$ Centro de Investigación de Polímeros Avanzados. CIPA. Conicyt-Regional R08C1002. Beltrán Mathieu 224. Concepción, Chile
}

(Received: October 9, 2013 - Accepted: March 17, 2014)

\begin{abstract}
Polypropylene composites with 5 to $10 \%$ of $\mathrm{SiO}_{2}, \mathrm{Al}_{2} \mathrm{O}_{3}$ y $\mathrm{TiO}_{2}$ nanoparticles were synthesized. The oxides were obtained using the sol-gel technique and were added to the molten polypropylene. The morphology of nanoparticles was observed by scanning electron microscopy and showed that the incorporation of $\mathrm{TiO}_{2}$ and $\mathrm{SiO}_{2}$ gels produces high dispersion of the filler, while the use of $\mathrm{Al}_{2} \mathrm{O}_{3}$ results in aggregates of these nanoparticles in the polymer matrix. The X-ray diffractogram of the composites revealed a displacement of characteristics lines of polypropylene and an increment of the interplanar spaces, indicating some interaction between the components and the predominance intercalation of oxides. Through FT-IR it was noticed the presence of functional groups attributable to the filler nanoparticles.
\end{abstract}

The crystallization, the fusion behaviour and the thermal stability of the composites was studied using differential scanning calorimetry and thermogravimetric analysis it was found a reduction in the crystallization temperature and increment in the thermal stability of the polypropylene matrix due to the action of the silica, alumina an titania nanoparticles.

Keywords: sol-gel, nanoparticles, polypropylene, composites, characterization

\section{INTRODUCTION}

The polymer-inorganic material nanocomposites have been profusely studied, and one of the characteristics in obtaining them is that they significantly improve the thermal and mechanical properties of the initial polymer $(1,2)$. On the other hand, polypropylene is a convenient thermoplastic with an adequate balance between processing and performance (3). Its fusion temperature $\left(162-165{ }^{\circ} \mathrm{C}\right)$ is high enough to resist hot water but low enough to make thermoforming easier, for this reason it is highly used in various applications, due to its low cost, low density and high thermal stability, corrosion resistance, etc. The formation of polypropylene nanocomposites has been a way to increase its use and reutilization; considering that it reaches around $20 \%$ of the worldwide production of polyolefins, its potential recycling and low cost make it more commercially attractive. Looking for new applications is what has motivated the interest in improving its mechanical and thermal properties through the synthesis of inorganic polypropylene-filler nanocomposites $(4,5)$.

There has been much interest by researchers in developing the proper nanofillers to interact with polymers, especially with polyolefins, due to their low affinity (6), several publications show the technical difficulties of achieving that goal. In most of these studies there have been obtained well dispersed and intercalated polyolefins-clay mixtures instead of completely exfoliated nanocomposites (7). It has been proposed that the increment in the polar host interaction force with a non-polar polymer can be achieved by reducing the surface energy of the filler (inorganic component) and improving contact of adhesion between the filler and the polymer $(8,9)$. One to the paths used to synthesize polyolefins nanocomposites is the sol-gel technique (10), by which metal oxides are obtained at ambient temperatures, starting with metal molecular precursors. Even though it has been successfully incorporated nanofillers to several polymers (11), there has not been enough success in polyolefins, such as polyethylene and polypropylene, due to the low solubility of these polymers in ordinary solvents and its elevated crystallinity. In this paper it was studied the reinforcement offered by $\mathrm{SiO}_{2}, \mathrm{Al}_{2} \mathrm{O}_{3}$ and $\mathrm{TiO}_{2}$ to polypropylene (PP); the oxides, synthesized by sol-gel technique, are incorporated to the molten polymer. The microestructural and morphological characterization of the nanocomposite was realized using X-rays diffraction (DRX), Infrared spectroscopy (FT-IR) and scanning electron microscopy (SEM). In order to study the reinforcement in the thermal properties of the nanocomposites, a thermogravimetric analysis (TGA) was done and the analysis by differential scanning calorimetry (DSC).

\section{Experimental Part}

Obtaining the $\mathrm{PP}-\mathrm{SiO}_{2}, \mathrm{Al}_{2} \mathrm{O}_{3}$ and $\mathrm{TiO}_{2}$ nanoparticles composite

The silica and alumina are obtained from an alcoholic solution (ethanol and 2-butanol) of the precursors tetraethyl-orthosilicate (TEOS) (Aldrich, 99,999 $\%$ ) and aluminum secbutoxide (SBA) (Sigma Aldrich, 99,99\%) respectively; the homogenization of the mixture is achieved by agitation at $40^{\circ} \mathrm{C}$. The TEOS and SBA reaction was catalyzed in an acid solution (, maintaining the molar ratio $\mathrm{HCl} /$ Precursor equal to $1,85 \times 10^{-2}$ and the $\mathrm{H}_{2} \mathrm{O} \square$ Precursor ratio equal to 10 for TEOS and 3 for SBA. The titania is obtained by dissolving the titanium tetraisopropoxide (TTIP) (Aldrich, 99,999 \%) in ethanol, this solution is mixed with a water-ethanol solution $\left(\right.$ ratio $\mathrm{H}_{2} \mathrm{O} / \mathrm{TTIP}=10$ ) added by dripping and immediately starts the precipitation of solid titanium oxide. This solid is then filtered and washed with ethanol. Then the $\mathrm{Si}, \mathrm{Al}$ and $\mathrm{Ti}$ gels were dried at $70{ }^{\circ} \mathrm{C}$ and calcined at $450{ }^{\circ} \mathrm{C}$. The oxide particles were ground. The average particle size of these is $12 \mathrm{~nm}$. The samples were kept in the desiccators to prevent them from absorbing moisture.

The polypropylene (PP) used is a pure polymer, provided by Petroquim PH1310 Homopolymer for injection; which was used without being chemically modified. The PP- oxide nanoparticles composites were prepared by incorporating the oxides to the molten polypropylene (PP), and in order to obtain them it was used a polymer mixer Thermo Haake (Model Rheomix 600). The temperature of the mixture was maintained at $190^{\circ} \mathrm{C}$ and the rotation speed at $60 \mathrm{rpm}$, the mixture remained under these conditions for $15 \mathrm{~min}$. With this procedure, the polymer and the oxides are pressed by the transversal forces that assist in the dispersion of the oxides. The content in the PP oxide composites was 5 and $10 \%$. Table 1 shows the designation that the PP-oxide nanoparticles will be given in this paper.

Table 1: Designation of the composites PP - nanoparticle of oxide of agreement to the content and type of oxide

\begin{tabular}{|c|c|}
\hline Name & $\begin{array}{c}\text { Content of oxide } \\
\text { (\% weight) }\end{array}$ \\
\hline PP-5- $\mathrm{SiO}_{2}$ & $5 \% \mathrm{SiO}_{2}$ \\
\hline PP-10- $-\mathrm{SiO}_{2}$ & $10 \% \mathrm{SiO}_{2}$ \\
\hline PP-5- $\mathrm{Al}_{2} \mathrm{O}_{3}$ & $5 \% \mathrm{Al}_{2} \mathrm{O}_{3}$ \\
\hline PP-10- $\mathrm{Al}_{2} \mathrm{O}_{3}$ & $10 \% \mathrm{Al}_{2} \mathrm{O}_{3}$ \\
\hline PP-5- $\mathrm{TiO}_{2}$ & $5 \% \mathrm{TiO}_{2}$ \\
\hline PP-10- $\mathrm{TiO}_{2}$ & $10 \% \mathrm{TiO}_{2}$ \\
\hline
\end{tabular}


Characterization of PP- oxide nanoparticles composites

The morphology of the samples and the particle size of the oxide was studied by scanning electron microscopy (SEM) using a microscope JEOL (Model JSM $6380 \mathrm{LV}$ ). The samples were gold-leaved to obtain electronic images and for the microanalysis, in the former, the analysis of signals of gold was corrected, as well as other metals different from the object of study. It was also evaluated the shape and size, and was done analysis of the oxide particles.

The crystalline structure of the composites obtained was examined by X-ray diffraction (XRD) using a Bruker diffractometer (Model D4 Endeavor) that operates at $40 \mathrm{KV}$ and $20 \mathrm{~mA}$. The step size was $0,02^{\circ}(2 \theta)$ and the time/ step $0,4 \mathrm{~s}$, the measurements were taken in between 2 and $90^{\circ}$ to the pulverized samples.

The Infrared spectroscopy was used to obtain qualitative information regarding the functional groups and the chemical characteristics of the prepared composites. The infrared absorption spectrum was obtained using a Nicolett FT-IR spectrophotometer (model Nexus) at ambient temperature between 4000 and $400 \mathrm{~cm}^{-1}$, pellets with $\mathrm{KBr}$ were used as a support of the samples.

The crystallization and melting studies of the prepared composites were carried out with a Mettler Toledo DSC (Model DSC 822) equipped with a thermal analysis data STAR ${ }^{\mathrm{e}}$ software system. Samples of around $5-10 \mathrm{mg}$ were run at a heating rate of $10^{\circ} \mathrm{C} / \mathrm{min}$ under a nitrogen atmosphere between 30 and $200^{\circ} \mathrm{C}$, to remove any previous thermal history. In the DSC, the second heating curve obtained as an endothermic peak $\left(\mathrm{T}_{*}\right)$ results from the melting of solid crystalline state to molten amorphous state that follows the endothermic enthalpy change $(\Delta \mathrm{H})$. In these DSC studies, the crystallization or cooling curve is obtained as the exothermic peak $\left(\mathrm{T}_{c}\right)$ that characterizes the enthalpy change during the cooling cycle. The samples were heated up to $200{ }^{\circ} \mathrm{C}$ per $5 \mathrm{~min}$ and then they were cooled down at ambient temperature at a cooling rate of $10{ }^{\circ} \mathrm{C} / \mathrm{min}$. The crystallinity degree $\left(\mathrm{X}_{\mathrm{c}}\right)$ was also obtained from the exothermic peak.

The thermal stability of PP and of $\mathrm{PP}-\mathrm{SiO}_{2}, \mathrm{Al}_{2} \mathrm{O}_{3}$ and $\mathrm{TiO}$ nanoparticles composites were investigated by a non-isothermal thermogravimetric analysis, it was used a thermogravimetric analyzer TA Instruments (Model Q 50). Samples of approximately $6 \mathrm{mg}$ were heated between 25 and $600{ }^{\circ} \mathrm{C}$, at a heating rate of $10^{\circ} \mathrm{C} / \mathrm{min}$ in a nitrogen atmosphere.

\section{RESULTS AND DISCUSSION}

The x-ray diffraction study was used to identify the crystalline structures in the sol-gel oxides and in the PP-oxide nanoparticles composites. In an exfoliated structure nanocomposite the diffraction lines of the fillers would disappear or attenuate, and in one of intercalated structure there should appear new diffraction lines. Figure 1 shows the diffractograms of the oxides. The analysis of the $\mathrm{SiO}_{2}$ sol-gel show the amorphous structure obtained, result that agrees with the information found in literature for similar preparations (12). A wide peak appears at $22^{\circ}$ associated to the typical diffraction of the amorphous $\mathrm{SiO}_{2}$. It is not observed in the PP-SiO diffractograms (Figure 2) the apparition of new lines due to the addition of silica in the polypropylene matrix. The $\mathrm{Al}_{2} \mathrm{O}$, sol-gel obtained has a low degree of crystallinity, the wide peaks at $42^{\circ}$ and $65^{\circ}$ are characteristic of $\gamma$-alumina (13). In the PP- $\mathrm{Al}_{2} \mathrm{O}_{3}$ diffractograms (Figure 2) there are lines preserved which could be associated to the presence of alumina in the composite. The diffractogram of the $\mathrm{TiO}_{2}$ sol-gel indicates that after heating the gel a single anatase phase is obtained, which matches previous reports under the same preparation and heating conditions (14). In the composites $\mathrm{PP}_{-} \mathrm{TiO}_{2}$ (Figure 2) the diffraction titania lines are preserved in the crystalline anatase phase. These results could suggest the formation of agglomerates of the filler in the polypropylene matrix.

In order to identify the crystalline structure of the PP-oxide nanoparticles composites, the position, the shape and the intensity of the diffraction lines attributed to the polypropylene matrix is monitored. Table 2 shows the angle, the spacing and the intensity of the most intense diffraction lines of the PP that appear to values of $2 \theta$ of $16,37^{\circ}(6,33 \AA), 19,67^{\circ}(5,23 \AA), 21,60^{\circ}(4,77$ $\AA)$ and $25,31^{\circ}(4,12 \AA)$. The PP diffraction lines are slightly affected in their intensity by the addition of the oxides, which would imply a modification of the polymer's crystallinity. Displacements of these characteristic lines are observed at smaller angles and increment the spacing for the first two diffraction lines. These modifications suggest intercalation of oxides in the two loads studied (15). The addition of amorphous $\mathrm{SiO}_{2}$ to PP reduces even more the polymer initial crystallinity of the than the addition of $\mathrm{Al}_{2} \mathrm{O}_{3}$ in both contents studied. The composites $\mathrm{PP}-\mathrm{TiO}_{2}$ and $\mathrm{PP}-\mathrm{Al}_{2} \mathrm{O}_{3}$ with $10 \%$ of filler show greater intensity in the PP diffraction lines; similar results were found by Reynaud et al. (16) which are attributed to the potential absorption of X-rays by $\mathrm{TiO}_{2}$ and $\mathrm{Al}_{2} \mathrm{O}_{3}$. The presence of titania diffraction lines in the diffractogram of the composite enables to suggest that in their structure the intercalation of the oxide prevails.

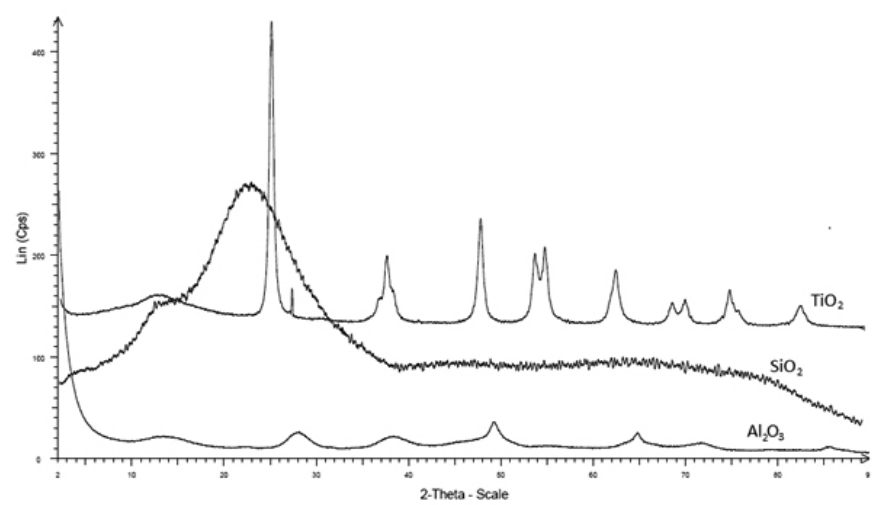

Figure 1. X-ray diffractogram of the oxides $\mathrm{SiO}_{2}, \mathrm{Al}_{2} \mathrm{O}_{3}$ and $\mathrm{TiO}_{2}$ obtained by sol-gel

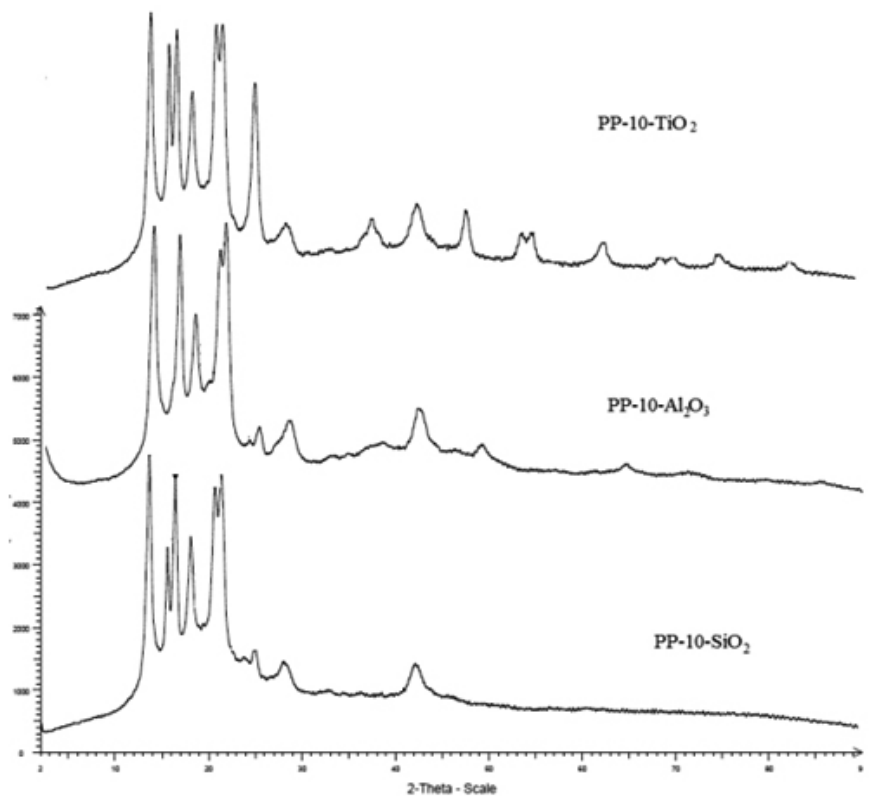

Figure 2. X-ray diffractogram of the $\mathrm{PP}-10-\mathrm{SiO}_{2}, \mathrm{PP}-10-\mathrm{Al}_{2} \mathrm{O}_{3}$ and PP$10-\mathrm{TiO}_{2}$ composites

SEM images of the composites enable to notice the structure of the nanoparticles. It is observed the space distribution of the phases and also the defects in the structure. The dispersion and adhesion of the $\mathrm{SiO}_{2}, \mathrm{Al}_{2} \mathrm{O}_{3}$ and $\mathrm{TiO}_{2}$ particles in the PP matrix could account for the interaction between both phases; this interaction leads to improving the thermal and mechanical properties of the composite. Figure 3 shows the micrography of the prepared composites, it is observed that the morphology of the surface of the polymer becomes irregular and rough due to the presence of oxides; also, it is observed fractures on fibre surface of some composites. In all the prepared composites, the size of the nanoparticles is smaller than $100 \mathrm{~nm}$.

The $\mathrm{TiO}_{2}$ and $\mathrm{SiO}_{2}$ particles have a spherical shape for the most part, but this is not the case of $\mathrm{Al}_{2} \mathrm{O}_{3}$ particles. It is clearly observed that for $\mathrm{SiO}_{2}$ and $\mathrm{Al}_{2} \mathrm{O}_{3}$ the size of these increases with content and its morphology changes, especially in the $\mathrm{Al}_{2} \mathrm{O}_{3}$. Results informed in literature (17), show that titania and silica nanoparticles are smaller than alumina particles on polypropylene. 
Table 2: Interplanar spaces (d) estimated by Bragg equation, angle (2 $\theta)$ and relative intensity of the most prominent PP diffraction lines associated to the $\alpha$-crystalline monoclinic phase.

\begin{tabular}{|c|c|c|c|c|c|}
\hline \multirow{3}{*}{$\mathrm{PP}-10-\mathrm{SiO}_{2}$} & $2 \theta^{\circ}$ & 13,93 & 16.72 & 20,97 & 21,64 \\
\hline & $\mathrm{d}(\AA)$ & 6,35 & 5,29 & 4,23 & 4,10 \\
\hline & I $(\%)$ & 100 & 92,3 & 88,6 & 94,5 \\
\hline \multirow{3}{*}{ PP-10- $\mathrm{TiO}_{2}$} & $2 \theta$ & 13,97 & 16,77 & 20,99 & 21,67 \\
\hline & $\mathrm{d}(\AA)$ & 6,33 & 5,28 & 4,23 & 4,10 \\
\hline & I (\%) & 100 & 94 & 96,7 & 96,2 \\
\hline \multirow{3}{*}{$\mathrm{PP}-10-\mathrm{Al}_{2} \mathrm{O}_{3}$} & $2 \theta$ & 13,98 & 16,75 & 21,09 & 21,71 \\
\hline & $\mathrm{d}(\AA)$ & 6,33 & 5,29 & 4,21 & 4,09 \\
\hline & I (\%) & 99,2 & 96,1 & 90,4 & 100 \\
\hline \multirow{3}{*}{ PP-5- $\mathrm{SiO}_{2}$} & $2 \theta$ & 13,97 & 16,75 & 21,07 & 21,67 \\
\hline & $\mathrm{d}(\AA)$ & 6,34 & 5,29 & 4,21 & 4,09 \\
\hline & I (\%) & 100 & 93,9 & 93,9 & 98 \\
\hline \multirow{3}{*}{$\mathrm{PP}-5-\mathrm{TiO}_{2}$} & $2 \theta$ & 13,96 & 16,74 & 21,01 & 21,65 \\
\hline & $\mathrm{d}(\AA)$ & 6,34 & 5,29 & 4,22 & 4,00 \\
\hline & I $(\%)$ & 100 & 94,9 & 87,5 & 95,5 \\
\hline \multirow{3}{*}{$\mathrm{PP}-5-\mathrm{Al}_{2} \mathrm{O}_{3}$} & $2 \theta$ & 13,92 & 16,70 & 21 & 21,61 \\
\hline & $\mathrm{d}(\AA)$ & 6,36 & 5,31 & 4,23 & 4,11 \\
\hline & I $(\%)$ & 100 & 93,5 & 91,4 & 93,9 \\
\hline
\end{tabular}

In the PP- $\mathrm{Al}_{2} \mathrm{O}_{3}$ composites there is lower dispersion of the alumina, the particles are not homogeneous in shape or size and there is predominance of agglomerated nanoparticles. It is also observed wide areas of fractures in the $\mathrm{PP}$. In the $\mathrm{PP}-\mathrm{SiO}_{2}$ composites, there is improvement in the oxide dispersion, spherical particles are predominant which size is smaller than $30 \mathrm{~nm}$; increasing the load of oxide, agglomeration of the oxide is produced and a
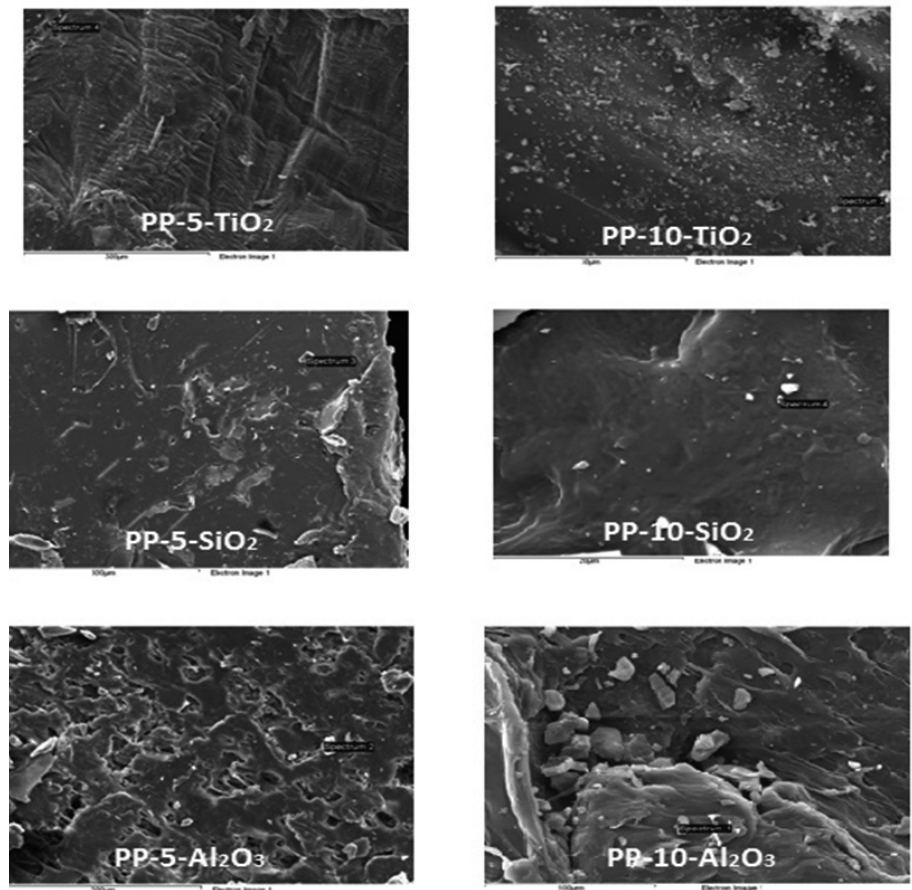

Figure 3. $\mathrm{SEM}$ image of $\mathrm{PP}-\mathrm{SiO}_{2}, \mathrm{TiO}_{2}$ and $\mathrm{Al}_{2} \mathrm{O}_{3}$ nanoparticles composites to the two loads studied.

slight deterioration in the dispersion. In the $\mathrm{PP}^{-\mathrm{TiO}_{2}}$ composites there are two types of particles observed with different geometries, spherical-shape particles and lengthened-shape particles; the size of these particles fluctuates between 15 and $40 \mathrm{~nm}$. At a higher titania content, it is observed a more homogeneous morphology and uniformity in the oxide dispersion.

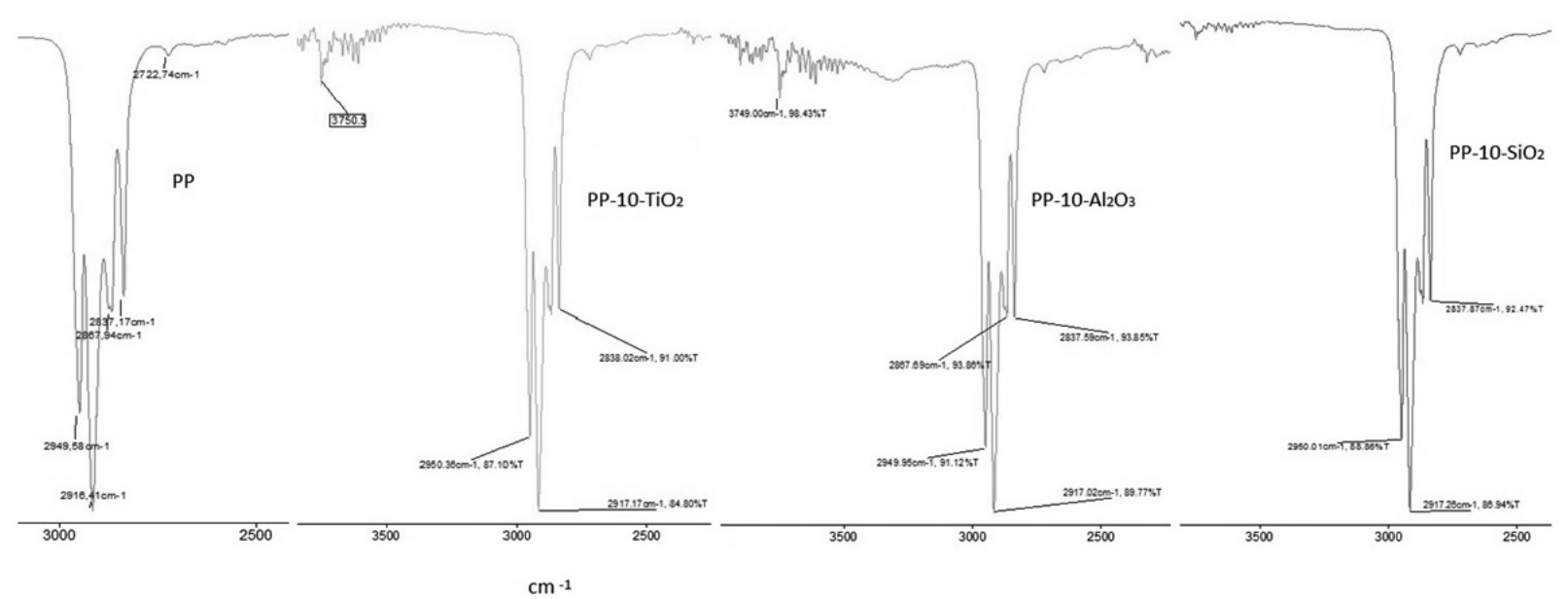

Figure 4. FT-IR spectrum of PP and PP-10-TiO, PP-10- $\mathrm{Al}_{2} \mathrm{O}_{3}, \mathrm{PP}-10-\mathrm{SiO}_{2}$ composites in the high area

The IR spectroscopy of the composites was used to obtain qualitative information regarding the presence of functional groups and chemical characteristics of the composites. As observed in Figure 4, the composites that contain $\mathrm{TiO}_{2}$ and $\mathrm{Al}_{2} \mathrm{O}_{3}$ show wide bands with low intensity located at about $3600-3800 \mathrm{~cm}^{-1}$, which have been associated to hydroxyl stretching due to isolated and terminal $-\mathrm{OH}$ groups (18), the presence of these is blurry in the composites with a lower content of nanoparticles. In the $\mathrm{PP}-\mathrm{SiO}_{2}$ composites, these bands do not appear or are quite diffused. Given the apolar characteristic of the polymer, it was expected that the interaction would not be through the nanoparticles $\mathrm{OH}$-groups. 


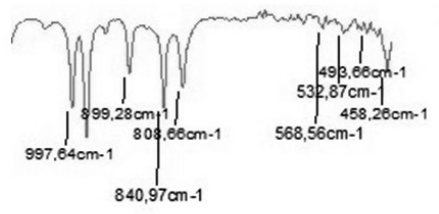

PP

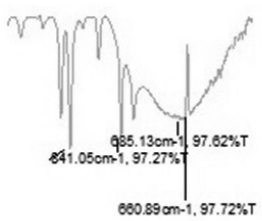

$\mathrm{PP}-10-\mathrm{TiO}_{2}$

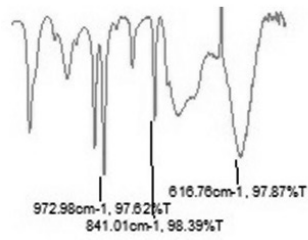

$\mathrm{PP}-10-\mathrm{Al}_{2} \mathrm{O}_{3}$

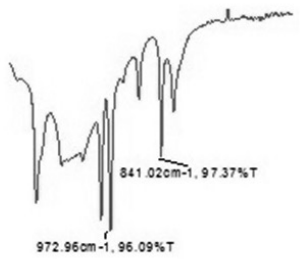

PP-10-SiO2

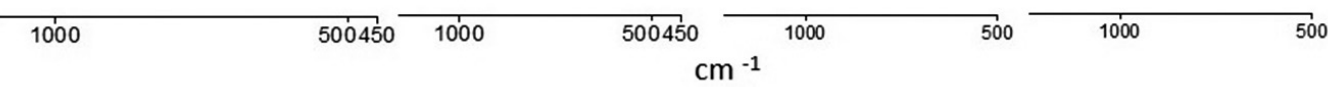

Figure $\mathbf{N}^{\circ}$ 5. FT-IR spectrum of PP, PP-10-SiO, PP-10- $\mathrm{Al}_{2} \mathrm{O}_{3}$ and $\mathrm{PP}-10-\mathrm{TiO}_{2}$ in the low area.

As observed in Figure 5, the pure PP shows several absorption bands in the low area of the spectrum, these areas cover a large portion of the characteristic vibrations of the $\mathrm{SiO}_{2}, \mathrm{Al}_{2} \mathrm{O}_{3}$ and $\mathrm{TiO}_{2}$ nanoparticles. In the $\mathrm{PP}-\mathrm{SiO}_{2}$ composites the absorption appears around $980 \mathrm{~cm}^{-1}$ is attributed to the stretching of the chemical bonds $\mathrm{Si}-\mathrm{OH}(18,19)$, since the intensity of this band increases with the $\mathrm{SiO}_{2}$ content present in the composite. It is not noticed clearly intense absorption bands at 1100 and $480 \mathrm{~cm}^{-1}$ associated to stretching vibrations and flexion of the $\mathrm{Si}-\mathrm{O}-\mathrm{Si}$ bonds. In the composites containing $\mathrm{Al}_{2} \mathrm{O}_{3}$ it is observed the presence of wide bands at 820 and $680 \mathrm{~cm}^{-1}$, which are associated to the stretching of Al-O-Al groups that are part of the alumina network (20). It is not observed the presence of Al-OH since the characteristic band of these groups appears at $1420 \mathrm{~cm}^{-1}$ and could be covered by absorptions present in pure $\mathrm{PP}$. The PP-TiO 2 composites do not show signs associated to Ti-OH groups, which could suggest condensation of these groups after the hydrolysis during the gel preparation. This is supported by the presence of a wide extension band located between 450 and $700 \mathrm{~cm}^{-1}$ which has been related to bending and stretching modes of Ti-O-Ti bonds and with the presence of Ti-O bonds in octahedral structures of $\mathrm{TiO}_{6}(21)$.

The DSC analysis was used to study blending temperature of pure PP and of PP-nanoparticles composites. It was studied the influence of $\mathrm{SiO}_{2}, \mathrm{Al}_{2} \mathrm{O}_{3}$ and $\mathrm{TiO}_{2}$ in the peak crystallization temperature $\left(\mathrm{T}_{\mathrm{c}}\right)$ and the crystallinity degree $\left(\mathrm{X}_{\mathrm{c}}\right)^{2}$, they were compared to the pure PP.

The degree of crystallinity the PP-oxide composites can be determined by its standard heat of fusion related to the pure polypropylene according to the following equation:

$$
\mathrm{X}_{\mathrm{c}}=\underset{\Delta \mathrm{H}^{*}}{\Delta \mathrm{H}_{\mathrm{m}}} \quad \times 100 \%
$$

Where $\Delta \mathrm{H}_{\mathrm{m}}$ is the heat of fusion of the PP-oxide composite standardized to the pure PP and

$\Delta \mathrm{H}^{*}$ is the heat of fusion of PP with $100 \%$ crystallinity. In order to apply the equation (1), the value of $\Delta H^{*}$ was obtained from literature (22) for a 100 $\%$ crystalline polypropylene, which value is 207,1 (Joule/g).

Table 3. Crystallization and fusion parameters of $\mathrm{PP}-\mathrm{SiO}_{2}, \mathrm{Al}_{2} \mathrm{O}_{3}$ and $\mathrm{TiO}_{2}$ nanoparticles composites to the various loads studied.

\begin{tabular}{|c|c|c|c|c|}
\hline Sample & $\mathrm{T}_{\mathrm{m}}\left({ }^{\circ} \mathrm{C}\right)$ & $\begin{array}{c}\Delta \mathrm{H} \\
(\mathrm{Joule} / \mathrm{g})\end{array}$ & $\mathrm{T}_{\mathrm{c}}\left({ }^{\circ} \mathrm{C}\right)$ & $\mathrm{X}_{\mathrm{c}}(\%)$ \\
\hline $\mathrm{PP}$ & 161,2 & 81,47 & 117,01 & 39,34 \\
\hline $\mathrm{PP}-5-\mathrm{SiO}_{2}$ & 165,8 & 76,27 & 113,45 & 36,83 \\
\hline $\mathrm{PP}-10-\mathrm{SiO}_{2}$ & 166,7 & 72,40 & 112,14 & 34,96 \\
\hline $\mathrm{PP}-5-\mathrm{Al}_{2} \mathrm{O}_{3}$ & 167,9 & 78,42 & 113,59 & 37,87 \\
\hline $\mathrm{PP}-10-\mathrm{Al}_{2} \mathrm{O}_{3}$ & 165,7 & 67,18 & 114,26 & 32,44 \\
\hline $\mathrm{PP}-5-\mathrm{TiO}_{2}$ & 160,0 & 72,21 & 113,08 & 34,87 \\
\hline $\mathrm{PP}-10-\mathrm{TiO}_{2}$ & 160,0 & 67,14 & 112,53 & 32,42 \\
\hline
\end{tabular}

Table 3 shows the values of the crystallization and fusion parameters of the prepared composites. It is observed a slight increment in the melting point $\left(T_{m}\right)$ of the polymer, when silica and alumina are incorporated to the polymeric matrix. The presence of $\mathrm{TiO}_{2}$ only produces a slight reduction in the $\mathrm{T}_{\mathrm{m}}$ value. The crystallization from the melt polymer shows a reduction of the $\mathrm{T}_{\mathrm{c}}{ }_{\mathrm{m}}$ and $\mathrm{X}_{\mathrm{c}}$ values.

Results published report that the addition of 10 to $50 \%$ of wood powder increases the $\mathrm{T}_{\mathrm{c}}$ value from $110{ }^{\circ} \mathrm{C}$ to $111-112{ }^{\circ} \mathrm{C}(23)$. Therefore, unlike lignocellulosic materials, the $\mathrm{SiO}_{2}, \mathrm{Al}_{2} \mathrm{O}_{3}$ and $\mathrm{TiO}_{2}$ nanoparticles used to reinforce the PP matrix did not act as nucleant agents during the crystallization; thus, they interfere with this process reducing the degree of crystallization ( $\mathrm{X}$ ) and the crystallization rate $\left(\mathrm{T}_{\mathrm{c}}\right)$. The heat of fusion of the PP $\left(\Delta \mathrm{H}_{\mathrm{m}}\right)$ decreases in the composites that contain nano-additives due to the reduction of the degree of crystallinity $\left(\mathrm{X}_{\mathrm{c}}\right.$ ); this was more evident in the composite containing $10 \%$ of $\mathrm{TiO}_{2}$. It is concluded in this research that by increasing the content of nanoadditives from 5 to $10 \%$, decreases the degree of crystallization of PP, which reinforce the idea that the particles do not act as nucleant agents in the process.

The results of the original PP thermal stability and of the PP- $\mathrm{SiO}_{2}$, $\mathrm{Al}_{2} \mathrm{O}_{3}$ and $\mathrm{TiO}_{2}$ nanoparticles composites, studied by thermogravimetry, are shown in Table 4 . It was considered the decomposition at $5 \%$ of mass as the beginning of a decomposition of the sample and the maximum mass loss rate as the derivative thermogravimetric DTG. It was also measured the final decomposition temperature.

Table 4. Parameters of thermal stability of $\mathrm{PP}-\mathrm{SiO}_{2}, \mathrm{Al}_{2} \mathrm{O}_{3}$ and $\mathrm{TiO}_{2}$ nanoadditives composites to the two contents studied.

\begin{tabular}{|c|c|c|c|}
\hline Sample & $\mathrm{T}_{5 \%}\left({ }^{\circ} \mathrm{C}\right)$ & DTG $\left({ }^{\circ} \mathrm{C}\right)$ & $\mathrm{T}_{\text {Final }}\left({ }^{\circ} \mathrm{C}\right)$ \\
\hline $\mathrm{PP}$ & 324,7 & 412,7 & 434,9 \\
\hline $\mathrm{PP}-5-\mathrm{SiO}_{2}$ & 329,7 & 428,6 & 456,1 \\
\hline $\mathrm{PP}-10-\mathrm{SiO}_{2}$ & 350,7 & 440,7 & 468,6 \\
\hline $\mathrm{PP}-5-\mathrm{Al}_{2} \mathrm{O}_{3}$ & 388,0 & 453,6 & 475,0 \\
\hline $\mathrm{PP}-10-\mathrm{Al}_{2} \mathrm{O}_{3}$ & 311,8 & 439,9 & 461,7 \\
\hline $\mathrm{PP}-5-\mathrm{TiO}_{2}$ & 395,2 & 446,6 & 464,4 \\
\hline $\mathrm{PP}-10-\mathrm{TiO}_{2}$ & 402,7 & 445,5 & 460,6 \\
\hline
\end{tabular}

As shown in Table 4, the decomposition of PP and of the composites that contain nano-additives occurs in only one stage. The presence of $\mathrm{SiO}_{2}, \mathrm{Al}_{2} \mathrm{O}_{3}$ and $\mathrm{TiO}_{2}$ nanoparticles delays the decomposition process of PP; except in the composite that contains a $10 \%$ of alumina. The highest thermal stability is achieved by the addition of 5 to $10 \% \mathrm{TiO}_{2}$ and $5 \% \mathrm{Al}_{2} \mathrm{O}_{3}$ where the beginning of the decomposition starts at temperatures around $70^{\circ} \mathrm{C}$ higher than those of the original PP.

\section{CONCLUSION}

In this paper there were prepared by melt polypropylene- $\mathrm{SiO}_{2}, \mathrm{TiO}_{2}$ and 
$\mathrm{Al}_{2} \mathrm{O}_{3}$ nanoparticles composites, obtained by sol-gel. It was studied the effects of two contents of these oxides. SEM images of the composites show the presence of nanoparticles of the oxides. It is concluded that titania is homogeneously dispersed in the polymer and that the dispersion is lower in the silica and in the alumina. The DRX results show variations in the diffraction lines of the polymer and it was noticed only the presence of $\mathrm{TiO}_{2}$ in the diffractograms of the composites. From this information, it is concluded that the nanoparticles have intercalated in the polymer. By FT-IR spectroscopy there were detected functional groups attributable to nanoparticle networks; it was not noticed in the study the chemical union between nanoparticles and the polypropylene matrix. From the DSC measurements, it was shown that the nanoparticles do not act as effective nucleant agents in the composites, reducing the crystallization rate of the composites and the degree of crystallinity, it was observed a slight increment in the fusion temperature. The TGA analysis revealed an important increment in the degradation temperature of the composites, depending on the type and content of the nanoparticles.

\section{ACKNOWLEDGEMENT}

The authors thank to the Direction de Investigation, of Universidad del Bío-Bío, for the financial support in this work.

\section{REFERENCES}

1. M. Alexandre and P. Dubois, Matr. Sci. Eng. 28, 1 (2000).

2. Leaversuch, R. , Plast. Technol., 47 (10), 64 (2001).

3. "Polyolefin Composites", Domesius Nwabunna and Thein Kyu, editores, John Wiley and Son ed. 2008, p. 31.

4. Sun, D., Zhang, R., Liu, Z., Huang, Y., Wang, Y., He, J., Han, B. and Yang G., Macromolecules, 38 (13), 5617 - 5624, (2005).

5. Ellis, T.S. and D`Angelo, J.S., Journal of Applied Polymer Science, 90 (6), 1639-1647 (2003).

6. Svoboda, P., Zeng, C., Wang, H., Lee, L., and Tomasko, D., J. Appl.
Polym. Sci., 85, 1562-1570, (2002).

7. Krishnamoorti, R., Vaia, R., and Giannelis, E. Chem. Mater., 8(8) , 17281134, (1996).

8. Jing, X., Zhao, W., and Len, L., J. Mater. Sci. Lett., 19, 377-379, (2000).

9. Chabert, E., Bornet, M., Bourgeat-Lami, E., Caveille, J-Y., Dendievel, R., Gauthier, C., Puteux, J-L., and Zaoui, A., Mater. Sci. Eng., 381, 320-330, (2004).

10. Brinker, C. J.; Scherer, G. W. Sol-Gel Science, The Physics and Chemistry of Sol-Gel Processing; Academic Press: San Diego, (1990).

11. Orellana, F., Lisperguer, J. and Perez-Guerrero, A., J. Chil .Chem. Soc., 56(1), 610-613 (2011)

12. Sadek, O.M., Reda, S.M. and Al-Bilali, R.K., Advances in Nanoparticles, 2, 165-175 (2013).

13. Karim, M.R., Rahman, M.A., Miah, M.A., Ahmad, H., Yanagisawa, M. and Ito, M., The Open Colloid Science Journal, 4, 32-36 (2011).

14. Pookmanee, P. and Phanichphant, S., J. of Ceramic Processing Research, 10(2), 167-170 (2009)

15. Morales, A.R., de Paiva, L.B., Zattarelli, D. and Guimaraes, T.R., Polímeros, 22(1), 54-60 (2012).

16. Reynaud, E., Jouen, T., Gauthier, C., Vieger, G. and Varlet, J., Polymer, 42(21), 8759-8768 (2001).

17. Plesa, I., Ciuprina, F., Notingher, P.V. and Panaitescu, D., Rev. Roum. Sci. Techn-Electrotechn. Et Energ., 56(3), 277-284 (2011).

18. Innocenzi, P., J. Non-Crystalline Solids, 316, 309-319 (2003).

19. U. Vijayalakshmi, A. Balamurugan and S. Rajeswari, Trends Biomater. Artif. Organs, Vol 18 (2), January 2005.

20. Tan, H. Ma, X. and Fu, M., Bull. Mater. Sci., 36(1), 153-156, (2013).

21. Laite, D., Costa, V., Martins, E., Soares, A., Gasparan, M. and Vasconcelos, W., Materials Sciences and Applications, 2, 1375-1382 (2011).

22. B. Wunderlich. Thermal Analysis, Academic Press, New York, 1990.

23. R.Bouza, A. Lasagabaster, M.J. Abad, L. Barral, J. Appl. Polym. Sci. 109, 1197, (2008). 